\title{
Self-assembled one-dimensional soft nanostructures
}

\author{
Sila Toksoz, Handan Acar and Mustafa O. Guler*
}

\author{
Received 18th March 2010, Accepted 15th June 2010 \\ DOI: $10.1039 / \mathrm{c} 0 \mathrm{sm} 00121 \mathrm{j}$
}

The self-assembly process is a bottom-up approach and is the spontaneous aggregation of many different subunits into well-defined functional structures with varying properties. Self-assembly is an attractive method to develop one-dimensional nanostructures and is controlled by many factors including temperature, $\mathrm{pH}$ and electrolyte addition. Novel self-assembled one-dimensional nanostructures are finding applications in regenerative medicine and electronics as well as in fabrication of nanoscale electronic, mechanic, magnetic, optical, and combinatorial devices. Their utility comes from their high ratio of surface area to volume, and their quantum-confinement effects. This paper reviews one-dimensional self-assembled organic nanostructures classified according to the noncovalent forces acting on their formation.

\section{Main text}

Nanostructures are defined as structures of which at least one dimension is smaller than 100 nanometres. Nanoscience is mainly concerned with how to control the dimensionality, size and shape of the nanostructures, and which novel physical properties - electrical, mechanical, optical or magnetic - these structures may possess. Over the last century, macroscale devices have been built and perfected, and the last few decades have been devoted to creating microdevices. However, applying this knowledge to the nanoscale has produced many difficulties in assembling atoms and molecules in a coordinated fashion. Mimicking nature could help us to overcome problems in molecular organization. From drug delivery systems comparable in size to a virus, to nanometre-sized electronic and optical devices, various applications have been inspired by nature, in which a small number of subunits is enough to create many types of complex nanostructures. ${ }^{1,2}$

Among nanoscale assembly techniques, top-down approaches have attracted attention for many years. But researchers in areas

UNAM-Institute of Materials Science and Nanotechnology, Bilkent University,06800 Ankara, Turkey.E-mail:moguler@unam.bilkent.edu. tr; Fax: +90 (312) 266 4365; Tel: +90 (312) 2903552 such as lithography and etching have faced difficulties related to the cost, process speed and diffraction limit of top-down devices. On the other hand, bottom-up approaches can offer large-scale, rapid, and low-cost production of nanostructures with a diverse range of starting materials. Self-assembly is a bottom-up approach and is the spontaneous aggregation of many different subunits into larger, well-defined, functional objects with different properties. Self-assembly is controlled by many factors including temperature, $\mathrm{pH}$, and electrolyte concentration. Novel selfassembled materials for both biological and nonbiological applications are being developed for regenerative medicine ${ }^{3-7}$ and electronics. ${ }^{8-11}$

One-dimensional (1-D) nanostructures have found widespread use in fabrication of nanoscale electronic, mechanic, magnetic, optical, and combinatorial devices owing to their high ratio of surface area to volume ${ }^{12}$ and quantum-confinement effects. ${ }^{12-14}$ By studying 1-D nanostructures, the effects of size reduction and dimensionality on mechanical and electrical properties can be investigated. An example of mechanical 1-D supramolecular nanostructures in nature can be seen in cytoskeletons. A cytoskeleton is a network of protein fibers in the cytoplasm, and is responsible for establishing the shape of the cell, providing mechanical strength, locomotion, intracellular organization of

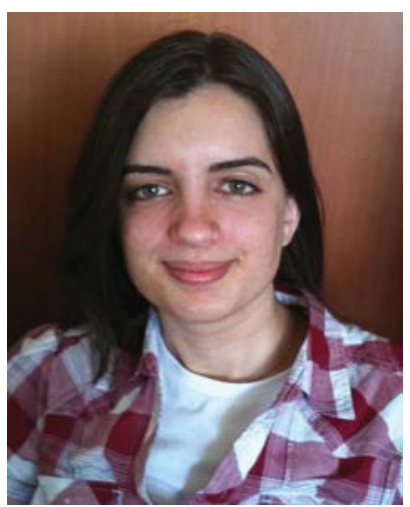

Sila Toksoz
Sila Toksoz graduated from the department of Molecular Biology and Genetics at Middle East Technical University, Turkey. She is currently a graduate student at UNAM-Institute of Materials Science and Nanotechnology. Her research interests include self-assembling peptide amphiphiles and their uses in regenerative medicine.

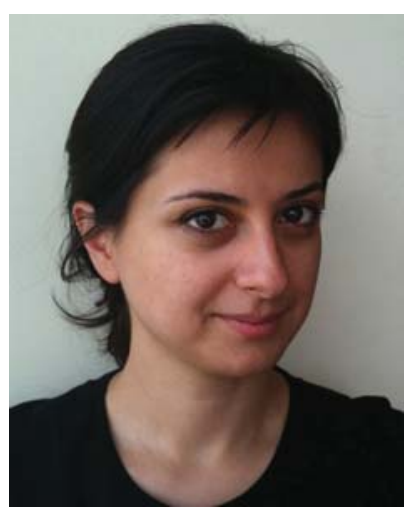

Handan Acar
Handan Acar took her undergraduate degree from Chemistry Education, Gazi University and M.Sc. from Physical Chemistry at Ankara University, Turkey. She is currently a graduate student at UNAM-Institute of Materials Science and Nanotechnology. Her research interests include self-assembling peptides and their uses in functional materials. 
organelles, and separating chromosomes into two daughter cells. Actin filaments, intermediate filaments and microtubules are the three main classes of protein filaments that form the cytoskeleton; actin and microtubules act in concert during cell movement and morphogenesis. ${ }^{15}$ Actin monomers polymerize to form thin fibers that are around $8 \mathrm{~nm}$ in diameter. Actin mediates muscle contraction and promotes protrusion of a migrating cell. Intermediate filaments are $10 \mathrm{~nm}$ in diameter, and include keratins, lamins, neurofilaments and vimentins. Microtubules are straight, hollow cylinders about $25 \mathrm{~nm}$ in diameter which are built by the self-assembly of alpha tubulin and beta tubulin dimers. They form a bipolar spindle that can separate chromosomes during cell division. Although nanoscience is still far away from being able to mimic such intricacy, biology continues to inspire the design of nanodevices. Amyloid fibrils are another natural example of 1-D nanostructures formed by very stable self-assembling peptides, and are known to play role in Alzheimer's disease. ${ }^{16}$ As a result of the biological relevance of 1-D aggregates in neurodegenerative diseases, the self-assembly mechanisms of such 1-D nanostructures are of interest to researchers.

The interactions that coordinate the amino acids and bases in natural 1-D systems are highly dynamic and often delicate, due to their relatively weak nature in comparison to that of covalent bonds. ${ }^{17}$ However, collectively sufficient number of these weak interactions can yield strong and stable aggregations. Biological $1-\mathrm{D}$ entities including viruses ${ }^{\mathbf{1 8}}$ and fungi ${ }^{19}$ have found use as templates for nanostructure synthesis, such as wires. ${ }^{20,21}$ An interesting study of Nam et al. combined virus-template synthesis with the genetic engineering of viral coat proteins, not only to make the coat more negatively charged in order to increase the metal ion binding, but also to facilitate the binding of nanowires to positively charged electrolyte polymer, with the ultimate aim of increasing the power of lithium ion batteries. ${ }^{22}$

Carbon nanotubes (CNT) are very interesting 1-D nanostructures due to their unique electronic and outstanding mechanical properties. ${ }^{23}$ CNTs can be categorized into singlewall and multi-wall nanotubes. Single-wall CNTs are rolled single graphite sheets possessing a tubular nanostructure, and a high-aspect-ratio. Multi-wall CNTs comprise of an array of such nanotubes, which are concentrically nested like the annual

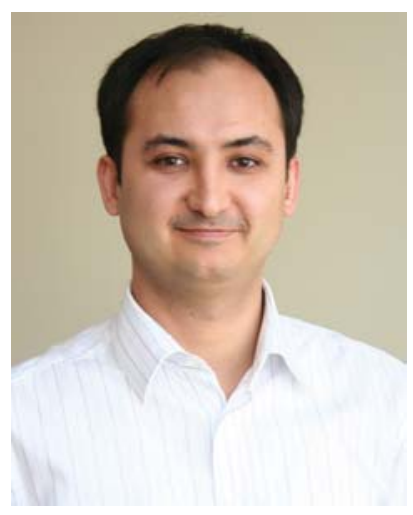

Mustafa O. Guler
Mustafa $O$. Guler is an assistant professor at UNAM-Institute of Materials Science and Nanotechnology, Bilkent University. He received $P h D$ degree in chemistry from Northwestern University in Evanston, IL, USA in 2006. After receiving his $P h D$, he had worked at the Institute for Bionanotechnology in Medicine at Northwestern University and Nanotope Inc. in Chicago, IL USA until 2008. His research is based on discoveries of nanostructures at the interface of chemistry, biology, and materials science.
Table 1 Strength and properties of non-covalent interactions. adapted from ref. 17,30

\begin{tabular}{|c|c|c|}
\hline Type of interaction & Strength $(\mathrm{kJ} / \mathrm{mol})$ & Properties \\
\hline Electrostatic & $50-300$ & Non-selective \\
\hline $\begin{array}{l}\text { Coordination } \\
\text { binding }\end{array}$ & $50-200$ & Directional \\
\hline $\begin{array}{l}\text { Hydrogen } \\
\text { bonding }\end{array}$ & $5-120$ & $\begin{array}{l}\text { Selective, } \\
\quad \text { directional }\end{array}$ \\
\hline$\pi-\pi$ Stacking & $0-50$ & Directional \\
\hline Solvophobic & $\begin{array}{l}\text { Depends on } \\
\text { solvent type }\end{array}$ & $\begin{array}{l}\text { Little directional } \\
\text { constraint }\end{array}$ \\
\hline van der Waals & $<5$ & $\begin{array}{c}\text { Non-directional, } \\
\text { non-selective }\end{array}$ \\
\hline Covalent & 350 & Irreversible \\
\hline
\end{tabular}

rings of a tree. Functionalization of carbon nanotubes via covalent and non-covalent methods has become widespread in order to decrease the toxicity of carbon nanotubes and increase their solubility. ${ }^{24-26}$ As they have already been covered by a number of researchers elsewhere ${ }^{27}$ and their formation is not directly related to self-assembly, carbon nanotubes will not be covered here.

In order to understand and control the self-assembly of supramolecular structures, the non-covalent interactions taking part in this process must be studied in detail. ${ }^{28,29}$ This review focuses on 1-D self-assembled organic nanostructures classified according to the forces acting on their formation, in order from the strongest interaction to the weakest (Table 1). The 1-D nanostructures covered in this work include nanowires, nanotubes, nanorods and nanoribbons.

\section{Electrostatic interactions}

Electrostatic bonds are based on Coulombic attraction between opposite charges. In host/guest chemistry, many receptors for anions and cations use electrostatic interactions to hold the guest in place. ${ }^{31}$ The principles of formation of nanostructures through electrostatic interactions can be read in Faul and Antonietti's review. ${ }^{30}$

Zhang et al. developed ionic self-complementary peptides, one of which is named RADA16, a peptide which forms nanofibers in aqueous solutions by using $\beta$-sheet structures. ${ }^{32}$ RADA16 contains negatively charged aspartic acids and positively charged arginine residues. Forming hydrogels in physiological media, the gels promoted the growth of neural cells in an integrated network that showed synaptic activity. ${ }^{33}$ In this case, the charged properties of the peptide nanostructures served not only for their selfassembly but also for guidance of the cells. These hydrogels have actually been shown to improve the attachment and differentiation of a variety of cell types, including stem cells ${ }^{34}$ and endothelial cells. ${ }^{35}$ In one study, the effects of the amino acid sequence on the adhesion of cells to the peptide fibers was studied to find out that more hydrophobic peptides resulted in less adhesion, probably due to conformational changes in the proteins decreasing the availability of the adhesion sites. ${ }^{35}$

Peptide amphiphile molecules ${ }^{36}$ exploit a number of noncovalent interactions to self-assemble. ${ }^{37}$ Two oppositely charged peptide amphiphiles have been shown to self-assemble into 1-D nanofibers by electrostatic interactions in aqueous solution at 
neutral $\mathrm{pH}^{38}$ The use of oppositely charged biomacromolecules to induce self-assembly has also been demonstrated, where heparin molecules screened the positive charge of a peptide sequence. ${ }^{39}$ Size of the macromolecules plays an important role in formation of nanofibers as well, ${ }^{40}$ as larger molecules including DNA and chondrotin sulfate result in gelation of positivelycharged peptides, whereas bovine serum albumin, a smaller molecule, can't induce self-assembly.

A very interesting approach of charge screening in the selfassembly process has been mixing positively charged peptide amphiphile molecules with negatively charged hyaluronic acid molecules to produce sacs, films and strings (Fig. 1). ${ }^{41}$ Unlike most systems based on oppositely charged macromolecules, these systems are ordered, stable in water, self-sealing and permeable to proteins.

$\mathrm{TZ1H}$, a 41 residue peptide with six heptad repeats of a coiledcoil structural motif, self-assembled into helical fibrils with diameters ranging from $40-100 \mathrm{~nm}$, via $\mathrm{pH}$ change. ${ }^{42}$ The design of the peptide, in which the isoleucine residues were chosen to favor formation of a trimeric coiled-coil structure, was inspired by the isoleucine zipper peptide GCN4-pII, ${ }^{43}$ which had been shown to form a three-stranded helical bundle. To achieve complete charge screening via electrostatic interactions between specific charged residues, namely e- and g- positions of the heptads, the structure was required to be a helical fibril of a three stranded rope. Histidine residues at the d-positions of alternating heptads served as the $\mathrm{pH}$-responsive unit of the TZ1H. At $\mathrm{pH}$ values close to the $\mathrm{p} K_{\mathrm{a}}$ of the imidazole group of histidine residues, protonation of the side chains affects the self-assembly process by causing destabilization in the structure of the helical fibril. A pH value between 6.5 and 8.0 made the peptide to hold an $\alpha$-helical structure; between 4.0 and 5.6, the peptides adopted a random-coil structure. At pH 5.8, a conformational transition from helix to coil occurred. Both conformations were shown to be fully reversible within the $\mathrm{pH}$ range from 4.0 to 8.0. At a basic $\mathrm{pH}, 8.2$, fibers larger than three-helix bundle fibers were observed; which were probably bundles comprised of smaller fibrils. Selfassembly can be controlled in a reversible manner through changes in environmental stimuli, as long as the concentration range is appropriate for assembly conditions.

Tetrapyrroles are large macrocyclic molecules containing four pyrrole rings. They self-assemble into light-harvesting and energytransferring nanostructures in biological systems. Porphyrins from the tetrapyrrole family are attractive building blocks to synthesize photocatalytic and light-responsive nanotubes; two oppositely charged porphyrins were employed to self-assemble through electrostatic interactions. ${ }^{44}$ It is possible to change the function and the structure of the nanotubes by modifying the porphyrin building blocks, suggesting a high degree of control over the nanotubes.

\section{Metal coordination}

Over the past few decades, many studies have been carried out regarding coordination polymers and crystal engineering of metal complexes; selective metal ion binding has been found to be a promising approach to control the fabrication of nanoscale self-assembled structures. In metal coordinated structures, metal ion functioning had been used along with some other noncovalent interactions ${ }^{45-48}$ including hydrogen bonding, $\pi-\pi$
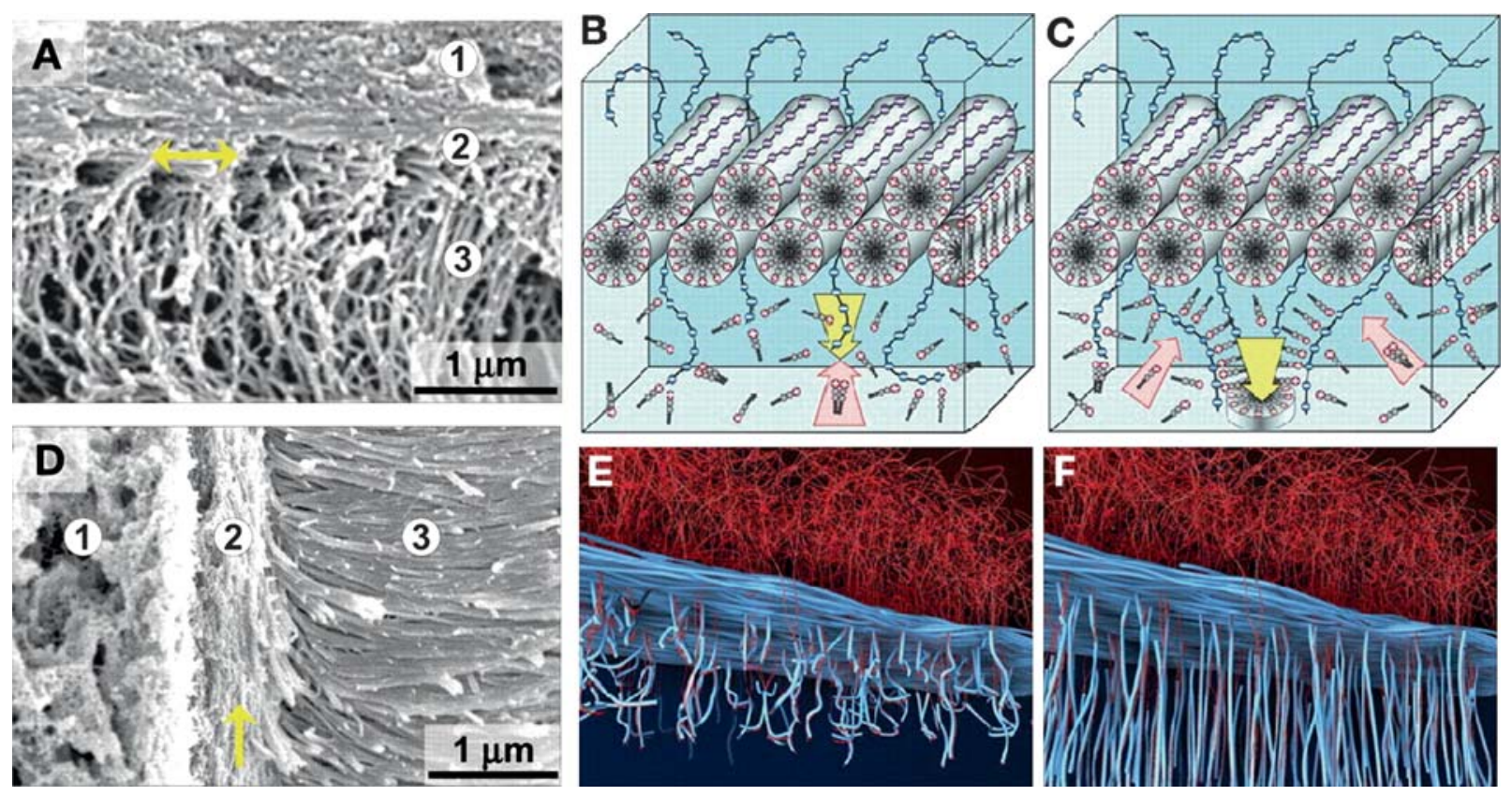

Fig. 1 A is the SEM image of the sac membrane after forming for $30 \mathrm{~min}$. The upper side is the hyaluronic acid (HA) solution and lower side the peptide amphiphile (PA) solution, with a solid membrane in between. D is the TEM image of a cross-section of the membrane, where the arrow in the second region indicates the parallel fiber region between the amorphous and perpendicular fiber zones. $\mathrm{B}$ and $\mathrm{C}$ show the physical barrier between the two solutions created by the nanofibers; the yellow arrow indicates the reptation of macromolecules into the PA solution due to osmotic pressure imbalance, and the pink arrow indicates the attraction of PA molecules to the polymer strands. E and F show the self-assembly of nanofibers and their perpendicular growth to the interface over time, while the polymer continues to diffuse into the PA solution. Reproduced with permission from ref. 41. 
stacking interactions and van der Waals forces. Potential applications of these nanostructures lie in the development of new materials, including metal-organic frameworks, ${ }^{49,50}$ with magnetic, non-linear optical and photoluminescent properties.

Metal centers interact with ligands via medium strength directional metal-ligand bonding. A broad knowledge of coordination chemistry contributes to the selection of appropriate metal-ligand pairs and binding modes for the assembly of supramolecular structures with differing shapes. A coordination system consists of a central metal atom, called the coordination center, ligated to other atoms, called ligands, where the coordination bonds are delocalized over the ligands, thus reducing the Coulomb repulsion between the electrons. The d-orbital occupation changes the symmetry of the metal coordination sites, thereby changing the supramolecular shape. To obtain the desired structure, the metal coordination environment and binding mode of the linkers must be carefully designed, where the shape is encoded both in the ligands and the metal ions. For the metal center, transition metal ions can be useful as they not only stabilize the structures but also interact with other elements, allowing construction of more complex structures. To form complex structures, the metal centers should be available for further coordination; bulky ligands can be used to hinder the attachment of same or other ligands to the metal centers, thereby preventing saturation of the metal centers.

While devising an approach for ion-controlled supramolecular assembly of 1-D nanofibers, one should consider one-turn helices, two-turn helices and macrocycles. ${ }^{28,51}$ Interactions happening inside the oligomers were observed to affect outer interactions; alkali cation binding promoted helix association, which in turn promoted fibril formation and aggregation. In a recent study, this interesting phenomena was studied in a family of foldamers and macrocycles based on the 1,8-naphthyridine and pyrimidine units, with internal cavities large enough to interact with oligoammonium cations. ${ }^{51}$ Conservation of helical conformations could be indicated by the necessity of the substrate to fit well with the helix pitch in the case of one-turn helices so that it bound to the helix fully; for two-turn helices, one-to-one binding of oligoammonium with appropriate bridge length caused rigidification of the helix only for bis-ammonium,

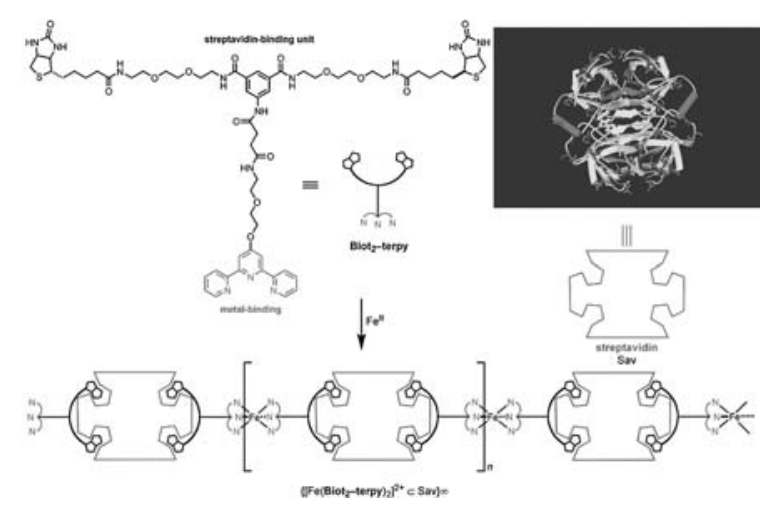

Fig. 2 Bis-biotinylated terpyridine forms a linear tetrabiotinylated connector, the $\left[\mathrm{Fe}\left(\mathrm{Biot}_{2} \text {-terpy }\right)_{2}\right]^{2+}$ complex, upon reaction with ferrous ion. The presence of streptavidin results in formation of linear coordination polymers. Reproduced with permission from ref. 49.
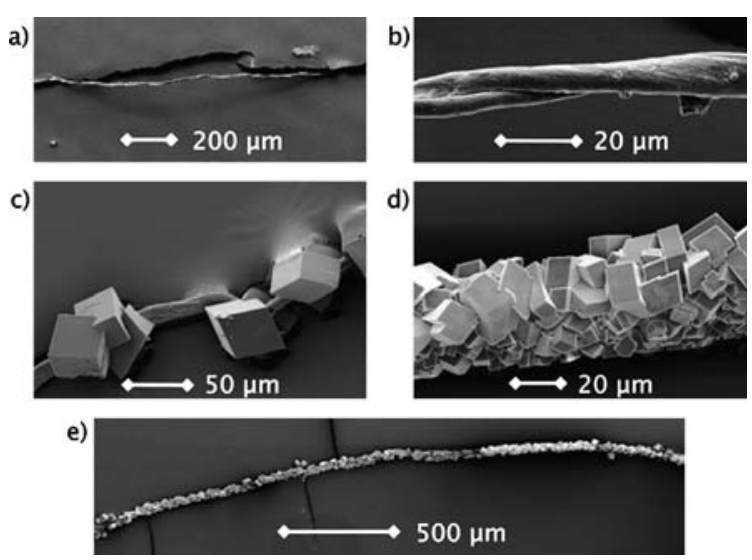

Fig. 3 SEM images of MOPF bundles containing $\mathrm{CaCl}_{2}$. (a) $8 \times 10^{-7} \mathrm{M}$ Fe solution containing $0.05 \mathrm{M} \mathrm{CaCl}_{2}, 5 \mathrm{~min}$ at $\mathrm{RT}$; and (b) a zoom into it. (c-e) Biomineralized bundles of $8 \times 10^{-6} \mathrm{M}$ Fe solution, $12 \mathrm{~h}$ : (c) $0.01 \mathrm{M}$ $\mathrm{CaCl}_{2}$; (d,e) $0.05 \mathrm{M} \mathrm{CaCl}_{2}$. Reproduced with permission from ref. 49.

which fit the length of the helix. These structures have been proven to be useful for studying the impact of guest binding within a cylindrical environment. The transition-metal connectors in conjunction with proteins are used to create 1-D metal-organic protein frameworks. ${ }^{49}$ It was demonstrated that streptavidin, a homotetrameric protein with four biotin binding sites, combined with a linear tetrabiotinylated connector, the $\left[\mathrm{Fe}\left(\mathrm{Biot}_{2}-\text { terpy }\right)_{2}\right]^{2+}$ complex bearing four biotin groups, with the aim of producing a collagen mimetic material for calcite biomineralization. Self-assembly took place through noncovalent interactions of coordination polymers and protein aggregates into a 1-D metal-organic protein framework (MOPF) to yield millimetre-sized 1-D matrices. Ferrous ions were used in the synthesis of $\left[\mathrm{Fe}\left(\mathrm{Biot}_{2} \text {-terpy }\right)_{2}\right]^{2+}$, as terpyridine readily interacts with those ions in a cooperative fashion (Fig. 2). To induce the biomineralization of calcite, carbon dioxide vapor was streamed over MOPF bundles for nucleation, growth and assembly of calcite microcrystals on the bundles (Fig. 3). The negatively charged glutamic acid and aspartic acid side chains are thought to have favored chelation of calcium.

Self-assembly of de novo designed peptides into well-designed structures can be achieved through an appropriately chosen metal ion. ${ }^{52-54}$ Selective recognition and binding of the metal ion to the peptide can induce a conformational change. Selfassembly of a fibril forming peptide, a structural variant of a three-stranded helical bundle forming a trimeric leucine zipper, was triggered by silver(I) ion binding to proximal histidine residues. ${ }^{52}$ The trigonal planar geometry in the metal ion binding site favored binding of silver(I) ions, which in the presence of softdonor nitrogen ligands can adopt a trigonal planar coordination. Alternative coordination geometry using ions like copper, zinc and nickel failed to induce self-assembly. The same peptide was shown to self-assemble via a $\mathrm{pH}$-dependent route in a previous study ${ }^{42}$ Although the morphology of fibers obtained by the two routes was similar, the lateral association between fibrils to form fibers larger in diameter was less extensive for silver ion induced fibrils; this might be related to the Coulombic repulsion due to the partial co-localization of positive charges by counterions. 
Metal ion induced fibers were positively charged due to the presence of metal ions, in this case one silver(I) ion per peptide; whereas $\mathrm{pH}$-induced fibers have a negative charge at neutral $\mathrm{pH}$.

$\mathrm{Cd}(\mathrm{II})$ centers are known for their use as metal coordination centers, because the $d^{10}$ configuration of cadmium complexes results in formation of various coordination geometries. Kong et al. reported that an imidazole-containing tripodal ligand reacted with $\mathrm{Cd}(\mathrm{II})$ complexes of bromide, tetrafluoroborate, and nitrate, and three new coordination polymers were obtained. ${ }^{55}$ In the presence of $\left[\mathrm{CdCl}_{4}\right]^{2-}$ as a counter anion, one of the complexes adopted a 1-D zigzag chain structure. The other two complexes adopted branched chain structures. The $\mathrm{Cd}$ (II) centers of the three complexes had different geometries such as distorted square pyramide, tetrahedron, and distorted octahedron. Tetrafluoroborate and nitrate anions were not found in the distorted geometries, but they had an impact on the self-assembly process, therefore on the final framework. The obtained coordination polymers demonstrated photoluminescence, as all complexes exhibited a blue fluorescence at room temperature in the solid state and could serve as a good candidate for photoactive materials.

Dendron-rod-coils (DRC), having a unique triblock architecture, self-assemble into 1-D nanoribbons which have found use as a template for the synthesis of cadmium sulfide nanohelices. ${ }^{56,57}$ Cadmium sulfide semiconductors have potential photovoltaic applications. Cadmium ions have an affinity towards the hydroxy containing dendron region of the ribbons over the organic solvent. ${ }^{56}$ After exposure to hydrogen sulfide gas, the localized cadmium ions started to nucleate and grow as cadmium sulfide on one face of the twisted ribbon to form nanohelices with a pitch 40$50 \mathrm{~nm}$, nearly twice that of ribbons. Nucleation happened in many points at the same time, as revealed by TEM image (Fig. 4). In some cases, double coils were encountered, possibly due to mineralization happening at both faces of the ribbon.

It is possible to produce highly conductive, uniform silver nanowires by using $4 \times 4$ DNA nanoribbons as a scaffold..$^{58}$ The

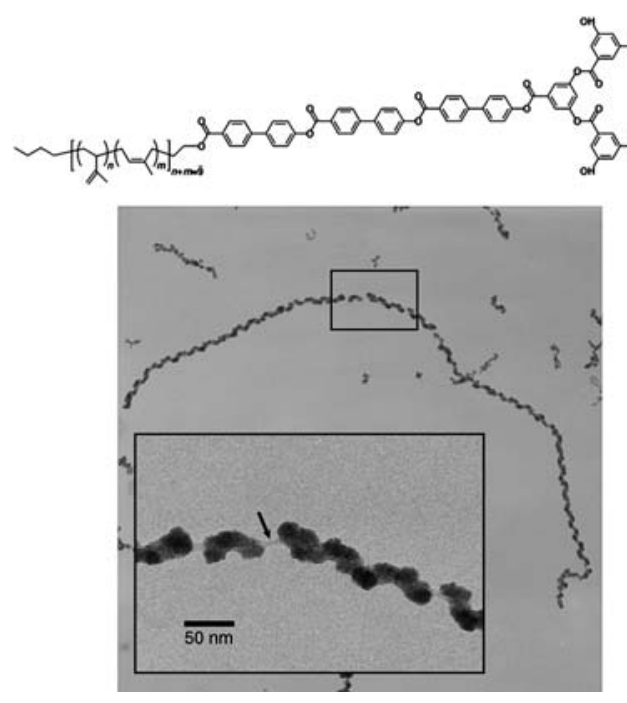

Fig. 4 Chemical structure of the dendron-rod-coil molecules and TEM image of cadmium sulfide precipitated in a suspension of DRC nanoribbons, at an early stage growth. The inset shows the start of nucleation at different points and the organic ribbon under sections of $\mathrm{CdS}$ as indicated by the arrow. Reproduced with permission from ref. 56 .
DNA nanoribbons were obtained through the self-assembly of a four-arm junctions oriented synthetic DNA nanostructure. These uniform-width nanoribbons were coated with silver to generate conductive nanowires. The metallized nanoribbons were $35 \mathrm{~nm}$ high, $43 \mathrm{~nm}$ wide and up to $5 \mu \mathrm{m}$ long. These nanostructures had been shown to have higher conductivity compared to previously generated DNA templated silver nanowires. ${ }^{59}$

\section{Hydrogen bonding}

Arguably the most important non-covalent interaction in the self-assembly process is hydrogen bonding, due to its directionality and strength. The hydrogen atoms act as a bridge between two electronegative atoms; the hydrogen bond donor group consists of an electronegative atom bound to a hydrogen atom that has a small positive charge due to dipole formation, and the hydrogen bond acceptor group consists of a dipole where the interacting atom of the acceptor group has a source of electrons.

The enthalpy of the hydrogen bond-based self-assembled systems must be balanced in consideration of the enthalpic loss and entropic gains due to hydrogen bonding and stacking interactions/ hydrophobic effects, respectively. ${ }^{60}$ Generally, hydrogen bonding is not the sole interaction in the self-assembly process; it is usually accompanied by other non-covalent interactions which have lower energies. Although hydrogen bonds are mostly used for constructing 2-D and 3-D nanostructures due to their selectivity and high directionality, ${ }^{61}$ there are also 1-D nanostructures which are self-assembled through hydrogen bonding interactions. ${ }^{62}$

Macrocycles containing an even number of alternating D- and L-amino acids, developed by Ghadiri and co-workers, were assembled into nanotubes by orthogonal hydrogen bonding, with the hydrogen bonds of the tubular structures perpendicular to the plane of the individual molecules (Fig. 5). ${ }^{63}$ In the design of the four cyclic peptides, four nonpolar amino acids and one polar amino acid were employed. Nonpolar residues were chosen to

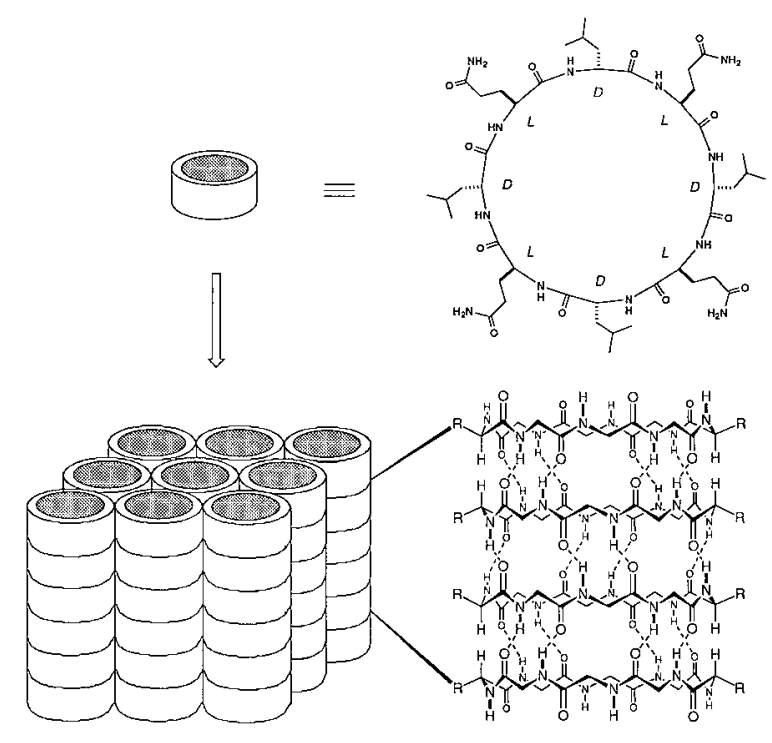

Fig. 5 Alternating D- and L-amino acids assembling into cyclic peptide nanotubes via the antiparallel ring stacking. Extensive intersubunit hydrogen bonding can be seen in the sketches. Reproduced with permission from ref. 63 . 
study the effects of increasing hydrophobic surface contact; the polar residue, glutamine, was selected because of its hydrogenbonding donor/acceptor capability and its possible participation in intra- and intertubular hydrogen bonding interactions, thus contributing to the structural stability of the system. Similar designs have been shown to form transmembrane channels for ion transport. ${ }^{64}$

Peptide amphiphile design of Hartgerink et al. was first presented in a biomineralization study, ${ }^{36}$ where the amphiphilic molecule consisted of a hydrophilic peptide headgroup, consecutive cysteine residues for formation of disulfide bonds, a flexible linker region, a phosphorylated serine residue for inducing biomineralization and a hydrophobic alkyl tail. A study of the self-assembly mechanism of peptide amphiphiles by Velichko et al. revealed that hydrogen bonding is the main interaction contributing to the final 1-D shape ${ }^{65}$ In their model, the headgroups were designed as electroneutral in order not to calculate the effects of electrostatics in the self-assembly process. This design enabled them to perform the Monte Carlo-stochastic dynamics simulations in a reasonable time and still capture various aspects of the process. Their coarsegrained model states that transitions from random molecules in solution to different micellar structures are based on the interaction between hydrophobic interactions and hydrogen bonding. Paramonov et al. designed 26 different peptide amphiphiles to study a number of parameters in self-assembly such as amino acid choice, directionality of hydrogen bonding and the reasons that the nanofiber structure is favored over other structures. ${ }^{66}$ They found that the amino acids near the alkyl tail of the peptide amphiphiles were the main contributors to the $\beta$-sheet structure, formed along the Z-axis of the fiber (Fig. 6). There, the disruption of the hydrogen bonds, which occurred by methylating the glycine amino acids forming the hydrogen bonds, resulted in a transition from nanofiber structure to nanovesicle structure after a specific number of methylations, due to the fact that the remaining energy was not enough to hold the supramolecular structure of a nanofiber together. Guler et al. developed peptide amphiphile molecules conjugated to nucleic acids, resulting in more thermally stable duplexes of the conjugate molecule-DNA/RNA in comparison to nucleic acid-nucleic acid duplexes. ${ }^{67}$ Such a molecule could be useful in RNA interference studies.

While studying the ability of very short aromatic peptides forming well-ordered amyloid fibrils, Reches et al. observed $\beta$-amyloid diphenyalanine structural motif of Alzheimer's

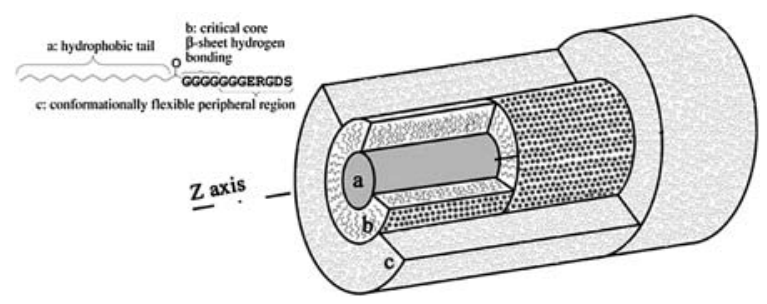

Fig. 6 The chemical structure and the cartoon of the peptide amphiphile nanofiber: The most inner region, (a) is the hydrophobic core composed of aliphatic tails. (b) The critical $\beta$-sheet hydrogen bonding portion of the peptide. (c) The peripheral peptide region, constitutes the interface between the fiber and the environment. Reproduced with permission from ref. 66 . disease self-assembling into 1-D nanotubes. ${ }^{68}$ The nanotubes worked well as a mold for casting silver metal nanowires, first by metal ion reduction and then enzymatic degradation of the mold. By using D-phenylalanine in the core structure of the peptide, the researchers achieved the construction of proteolytically stable nanotubes, which might have applications as biosensors. In another study, "teslian" (metal-insulator-metal) coaxial nanocables were developed by using the diphenyalanine peptide nanotubes as templates. ${ }^{69}$ Silver ions were reduced in the nanotubes which were then chemically modified with linker peptides consisting of a diphenylalanine motif and cysteine amino acid. The diphenylalanine motif was devised for interaction with the nanotube surface and cysteine in order to facilitate the imaging process of the structures, aided by gold ions that interact with the thiol group of the amino acid.

Hong et al. produced silver nanowires ${ }^{70}$ by reducing the silver ions in their organic nanotubes consisting of a reduced form of calix[4]quinone with four hydroquinone moieties. ${ }^{71}$ Of the eight hydroxyl groups, four outer groups led to self-assembled structures with intermolecular hydrogen bonding in the presence of water molecules. Repeating tubular calix[4]hydroquinone octamers formed short hydrogen bonds between themselves to stabilize a linear tubular polymeric structure, where intertubular $\pi-\pi$ stacking interactions contributed to the stability as well.

Hydrogen bonding is a powerful strategy in the self-assembly of 1-D nanostructures formed by dendrimeric molecules..$^{72}$ Some dendritic dipeptides were shown to self-assemble into helical porous 1-D nanostructures. ${ }^{73}$ The characterization of the helical nanostructures indicated that the controlled design of periodic non-biological porous structures in bulk and in solution was achieved by dendrimer chemistry. The molecular recognition and self-assembly process are strong enough to tolerate a range of modifications to the amphiphilic structure.

Dendron-rod-coils, which assemble into 1-D nanoribbons, form gel in certain solvents and at certain concentrations via hydrogen bonding in the hydroxyl rich regions and $\pi-\pi$ stacking of the conjugated segments. ${ }^{74-76}$ Zubarev et al. designed dendronrod-coil molecules as additives to modify the properties of polystyrene. ${ }^{76}$ The molecules were dissolved in organic solvents to form 1-D birefringent ribbon-like nanostructures with a width of $10 \mathrm{~nm}$ and a thickness of $2 \mathrm{~nm}$, even at an extremely dilute concentration (Fig. 7). When the gels were heated to a temperature above the boiling point of the organic solvent (e.g. styrene, dichloromethane, or acrylate derivatives), the gels did not melt revealing the irreversibility of the gel structure by temperature. To disassemble the gels, hydrogen bonding must have been disrupted by polar solvents. At 1 wt \% concentration, ribbons aggregated into bundles of 5 to 10 flat ribbons, where excess organic solvent use made the relatively isolated ribbons twist and gain a $20 \mathrm{~nm}$ pitch. The twisting probably protected the hydroxyl groups in the center of the ribbon from the hydrophobic solvent.

Lipid nanotubes are promising templates for producing 1-D nanostructures that provide organic, discrete, tubular structures composed of a very high number of identical lipid molecules, as Young's modulus of a single lipid nanotube was determined to be around $700 \mathrm{MPa} .{ }^{77}$ Various nanotube architectures are available with reference to the type of building block, as can be seen in Fig. $8{ }^{78,79}$ Helices can intertwine and produce aggregated helices; when helices reduce into rings, face-to-face non-covalent 

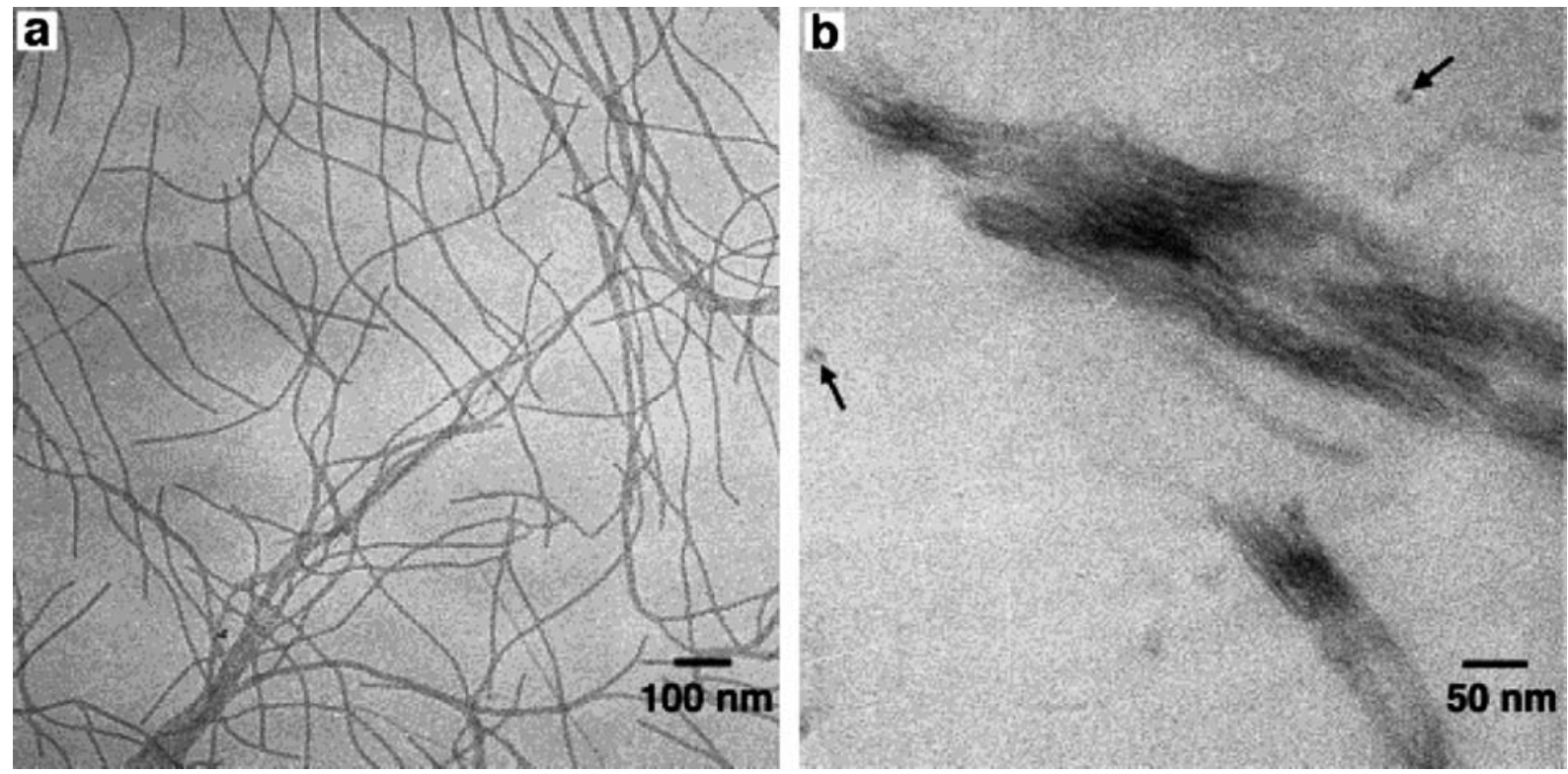

Fig. 7 (a) Bright field TEM image of unstained $0.004 \mathrm{wt} \%$ DRC molecules, dissolved in styrene. (b) High magnification TEM image of a thin slice of the scaffolded material, containing $1 \mathrm{wt} \%$ DRC molecules. Arrows represent perpendicularly placed individual bimolecular ribbons. Reproduced with permission from ref. 76 .

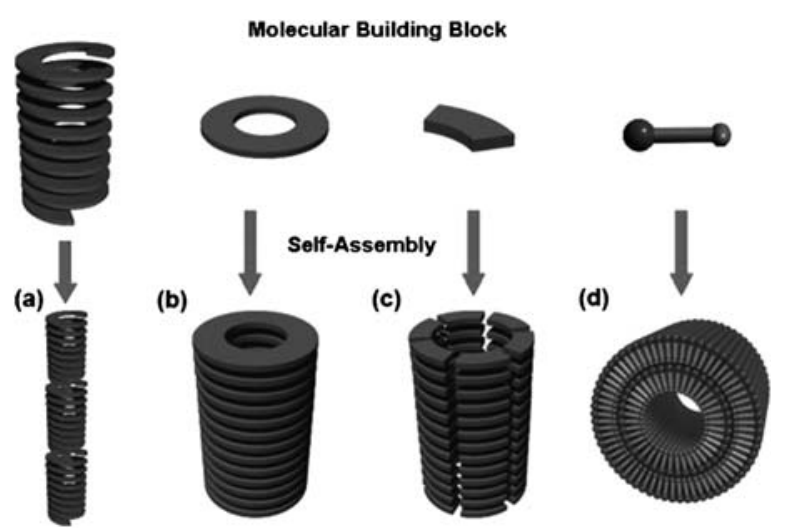

Fig. 8 Open-ended tubular architectures: (a) aggregated helices from a hollow helix, (b) stacked rings from a ring, (c) stacked rosettes from a rosette, (d) monolayer-based lipid nanotubes from an unsymmetrical bolaamphiphile. Reproduced with permission from ref. 78 .

interactions result in the formation of tubes; instead of rings, rosettes can arrange into stacked rosettes; amphiphilic molecules might roll into sheets to produce nanotubes. ${ }^{79}$

Controlling the inner and outer dimensions of nanotubes and the charges and functionalization of both sides are important in order to obtain well-defined and tailor-made architectures for many different purposes. Kameta et al. self-assembled fluorescent lipid nanotubes from an unsymmetrical bolaamphiphile to encapsulate and track the passage of guest molecules through the hollow nanotubes, in order to better understand how the molecules act while entering and exiting the cell through the channels of the lipid bilayer. ${ }^{80}$ The same group also developed cardanyl- $\beta$-Dglucopyranoside lipid nanotubes to reveal the role of water confined in a lipid nanotube by incorporating 8-anilinonaphthalene-1-sulfonate as a probe, with the ultimate aim of guest encapsulation. ${ }^{78}$ Hydroxyl groups of glucopyranoside covering the inner surfaces interacted with water molecules, lowering the solvent polarity to a value similar to that of propanol rather than bulk water.

In a recent study, formation of 1-D nanostructures on defected structures has been demonstrated. ${ }^{81}$ 2,6-naphtalene-dicarboxylic acid molecules were adsorbed on stepped (110) silver surfaces, producing mesoscale 1-D chains. The average length of the chains had a lower limit of $0.14 \mu \mathrm{m}$ with the longest chain being nearly five times longer; the average number of steps crossed by a single chain was 2.3. Using dimers of dicarboxylic acids, formation of chains was shown to be favored over formation of open-ended dimers. By density functional theory calculations, the main factor in the self-assembly of the chains was found to be robust hydrogen bonding, along with the directionality of the surface and flexibility of molecular structure. The carboxylic acid residues were proven to be protonated, so the possibility of covalent bond formation on the silver surfaces was eliminated.

\section{$\pi-\pi$ interactions}

Even though much weaker and less directional when compared to hydrogen bonds, $\pi-\pi$ stacking interactions also drive the selfassembly process for $\pi$-conjugated systems. The nature of $\pi-\pi$ interactions is not very clear, but it is suggested that the geometrical arrangement of the fragments, as well as $\pi$ electrons, contribute to these interactions. ${ }^{82}$ In order to obtain 1-D structures as end products, it is necessary to favor growth along the stacking direction rather than lateral growth along side chains. With the progression of efficient and high yield synthesis methodologies of bulk molecules ${ }^{83}$ like dendritic molecules and macrocycles, it has become possible to build nanoscale architectures. Arylene ethynylene macrocycles, ${ }^{84,85}$ molecules with large planar surfaces, minimal ring strain and highly tunable ring sizes of $0.5-5 \mathrm{~nm}$, have 
been employed mainly for the synthesis of 2-D and 3-D structures, ${ }^{86,87}$ as simple self-assembly methods ${ }^{88}$ resulted in the formation of agglomerates, aided by solvophobic interactions between the alkyl side chains. Balakrishnan et al. achieved the selfassembly of arylene ethylene macrocycles into 1-D nanofibers by implementing the sol-gel process. ${ }^{89}$ Cooling a homogenous solution results in the gelation of the molecules, which decreases molecular mobility, thus minimizing the lateral growth due to side chain association.

To achieve a more effective 1-D self-assembly, a carbonyl linkage addition created a structure where the alkyl chains and the core of the molecule were on the same plane (Fig. 9). ${ }^{88}$ This geometry enhances face-to-face $\pi-\pi$ stacking, and simplifies the self-assembly process so that dissolving the molecule in a solvent and dispersing the solvent into a poor solvent are sufficient to induce self-assembly into 1-D nanostructures, whereas the saddle-shaped molecules require the above mentioned sol-gel process or some other strictly-controlled method.

Another type of macrocycle, constituted from oligoamides, is known to form fibrillar structures. ${ }^{90}$ The self-assembly mechanism is suggested to rely on face-to-face stacking, aligning the macrocycles into nanotubes containing a large channel (Fig. 10). ${ }^{91}$ Such nanotubes are proposed to be used as transmembrane channels by modifying the side groups to tune the solubility and membrane compatibility of the macrocycles. Employing different functional groups resulted in differing pore diameters, thus affecting the conductance of the transmembrane channels, showing that it is possible to mimic the ion channels in biological membranes.

Engelkamp et al. demonstrated that the tuning of the supramolecular chirality of the 1-D objects can be done in a controlled way by simply controlling the strength and directionality of the non-covalent interactions. ${ }^{92}$ Disk molecules, derived from

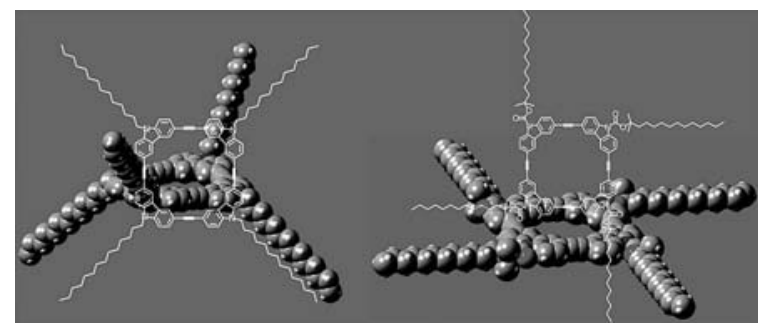

Fig. 9 The chemical structure and the two dimensional model of arylene ethylene macrocycles showing the effect of carbonyl group addition on the final structure. Reproduced with permission from ref. 88 .

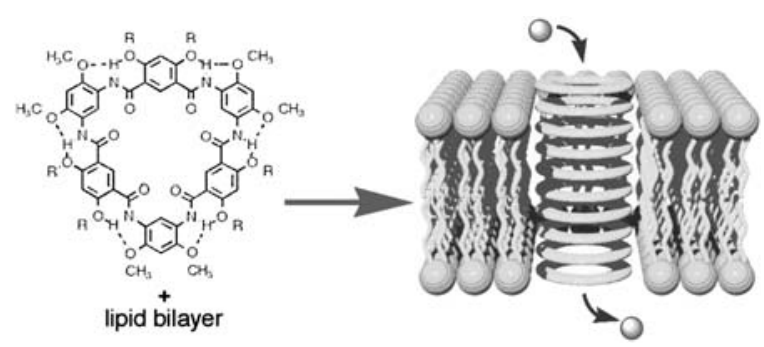

Fig. 10 Oligoamide macrocycles self-assembling into transmembrane channels through face-to-face stacking. Reproduced with permission from ref. 91. a phthalocyanine ring and covered with crown ether moieties, formed fibers with right-handed helicity through $\pi-\pi$ stacking, which eventually yielded superhelices with left-handed helicity. The advantages of using $\pi-\pi$ stacking in design of nanostructures are its relatively uncomplex method and the resulting high mobilities in electronic devices. High mobility is generally attributed to strong overlapping in a stack of neighboring molecules' electronic wave functions ${ }^{93}$ which increases bandwidth and consequently electrical conductivity. ${ }^{94}$

In the molecular electronics field, nanowires and nanocables self-assembled via $\pi-\pi$ stacking have been drawing attention..$^{95-97}$ This type of stacking is commonly observed in aromatic compounds with extended $\pi$ systems. To give an example, hexabenzocoronene is a polycyclic aromatic hydrocarbon (PAH) compound consisting of 13 fused benzene rings, and it was shown to self-assemble into nanocables. Researchers also devised a method for putting the cables into organic field effect transistors by using elastomer stamps. ${ }^{98}$ In another study, a derivative of hexabenzocoronene self-assembled into nanotubes in tetrahydrofuran, where the walls of the tubes consist of helical arrays of $\pi$-stacked coronenes covered by hydrophilic glycol chains (Fig. 11). ${ }^{99}$ The final structures have been found to be electroconductive and have a resistivity comparable to that of gallium nitride semiconductors.

Hexabenzocoronene had also been used for producing discotic liquid crystals, called mesogens, by chemically modifying the periphery of hexabenzocoronene, whose liquid crystalline phase showed a rapid switching process within the applied electrical field. ${ }^{100} \pi-\pi$ stacking and hydrogen bonding are the two synergistic intermolecular forces controlling the assembly of the central aromatic subunits of the liquid crystals.

\section{Solvophobic interactions}

Solvophobic interactions, which have little directional constraint, differ from the other non-covalent interactions in terms of inducing self-assembly that hydrophobic interactions are stabilized due to favorable entropy rather than favorable enthalpy, which might even be unfavorable as long as entropy is favored. The solvophobic parts of the molecules tend to associate to minimize their surface area contacting the solvent, whereas the
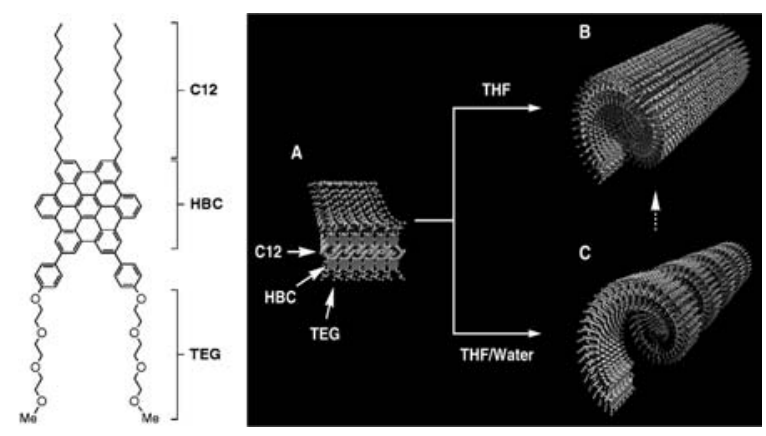

Fig. 11 The chemical structure of hexa-peri-hexabenzocoronene and the self-assembly mechanism into nanotubes and helical coils: (A) A graphitic bilayer tape; each layer consists of one dimensional columns of $\pi$-stacked hexabenzocoronene units. (B) A nanotube formed by tight rolling-up of the bilayer tape. (C) A helical coil formed by loose rolling-up of the bilayer tape. Reproduced with permission from ref. 99 . 
solvophilic parts try to remain in contact with the solvent. The two opposing forces compete with each other, one tending to decrease the interfacial area per molecule, the other tending to increase.

A solvophobic interaction is observed in solvents with a spatial hydrogen-bond network. It is thought to consist of two stages, namely solvation and interaction. According to Rodnikova et al., the solvation is related to the lability of the hydrogen-bond network, whereas elasticity of the network determines the interaction part. ${ }^{101}$

The importance of solvophobic interactions in the selfassembled nanostructures has been demonstrated in various studies. ${ }^{102,103}$ Designing molecules with lipid groups leads to molecules with amphiphilic features which are extremely important for self-assembly. ${ }^{104-106}$ To study the sole effects of the non-covalent forces, namely hydrogen bonding and solvophobic interactions, acting on the self-assembly of peptide amphiphiles, molecular simulations were used. ${ }^{107}$ It was found out that pure solvophobic interaction favored micelle production rather than 1-D nanofibers. However, there are a few studies where solvophobic interactions led to the self-assembly of the molecules into 1-D nanostructures. ${ }^{108,109}$

Macromolecular surfactants have been studied to understand the effect of the concentration of polymers, varying temperature and size on the final structure. ${ }^{108}$ Using diblock copolymers of a magnitude at least ten times greater than conventional nonionic surfactants, Won et al. achieved the formation of 1-D worm-like micelles in water at low concentrations of polymers. Solutions of polyethyleneoxide-poly(butadiene) polymers in a one to one ratio in weight, containing $17 \%$ or less block copolymer between 25-75 ${ }^{\circ} \mathrm{C}$, formed the basic shape of a cylinder. When the copolymer concentration was higher than $10 \%$, cylinders organized on a hexagonal lattice; a concentration between 5 and $10 \%$ resulted in a 1-D nematic phase, whereas in concentrations below $5 \%$, an isotropic solution of worm-like micelles was formed. The reason for selecting poly(butadiene) as the micelle core was the presence of double bonds in each repeat unit, which enabled crosslinking. Covalent bonding changed the viscoelastic properties of the micelles from the so-called "living" state ${ }^{110}$ to "permanent" state, indicating a transition from liquid to a fragile gel; the cylindrical morphology was preserved through all the process. The

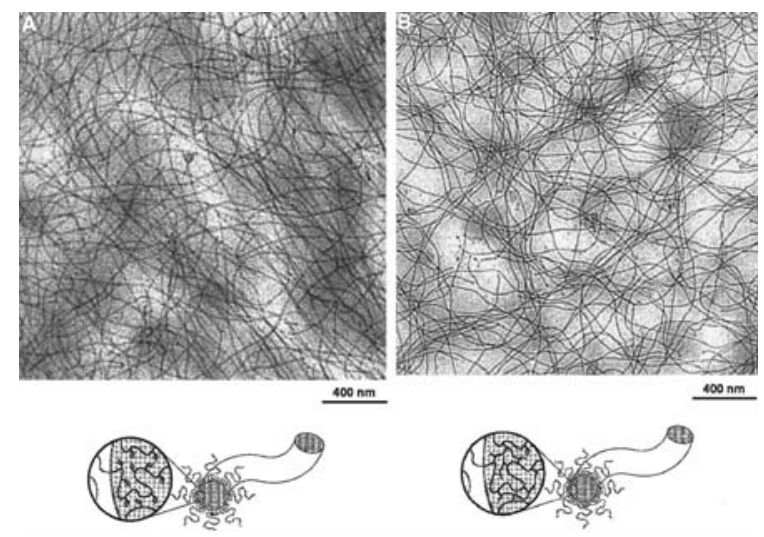

Fig. 12 Cryo-TEM images of the $1 \%$ unreacted (a) and $0.05 \%$ crosslinked (b) wormlike micelles. Cross-linked poly(butadiene) cores can be seen in below sketches. Reproduced with permission from ref. 108. stiffness of micelles was increased through the accompaniment of covalent bonding to sole van der Waals forces of liquid polymers. Cryo-electron micrographs revealed rubbery worm-like micelles that are several micrometres in length (Fig. 12).

Protein aggregation diseases, including type II diabetes among others which is characterized by the presence of amylin fibrils in the pancreatic islets, ${ }^{111}$ are becoming more common as the lifespan increases; however, no reliable treatments have been found yet. Some researchers work to limit or inhibit hydrogen bonding in these structures through primary sequence modification, ${ }^{112}$ as amyloid and amylin fibrils assemble from antiparallel oriented peptides, in which the amide bonds contribute to the hydrogenbonding network. Elgersma et al. studied the self-assembly of amylin amide bond derivatives into nanostructures with the ultimate aim to design $\beta$-sheet-breaker peptides to inhibit the aggregation of amylins. ${ }^{109}$ The peptide backbone was modified at alternate amide bonds to generate depsipeptides, $N$-alkylated peptides and peptoid-peptide hybrids as aggregation inhibitors. These peptides were expected to self-assemble into fibrils, whereas helical ribbons and nanotubes were observed indicating the absence of $\beta$-sheet formation. Replacing the backbone amide with an ester moiety or $\mathrm{N}$-alkyl group resulted in a weaker hydrogen-bond acceptor, which inhibited the aggregation of peptides into fibrils. For two of the peptides, which assembled into helical ribbons and nanotubes (Fig. 13), increased hydrophobicity is the proposed mechanism for the self-assembly.

\section{van der Waals interactions}

van der Waals interactions arise from fluctuations of the electron distribution of two closely spaced molecules. Shift of the electron cloud around the nucleus results in formation of an instantenous dipole within the molecule, which in turn partially charges the other molecule such that the partial positive charge of one molecule will be attracted to the partial negative charge of the other molecule. Although van der Waals interactions do not usually play the main role in self-assembly, there are a few studies showing its leading role in the assembly process. Zhang et al. developed a simple synthesis method for gold nanobelts, which are proposed to self-assemble through van der Waals interactions. ${ }^{113}$ Aurochloric acid $\left(\mathrm{HAuCl}_{4}\right)$ in polyvinylpyrrolidone (PVP) formed various structures; triangular plates, hexagonal plates, spheres, as well as nanobelts were observed. The nanobelts were uniform in diameter $(130 \mathrm{~nm})$ and thickness $(30 \mathrm{~nm})$. Polyvinylpyrrolidone adsorption on gold planes directs the

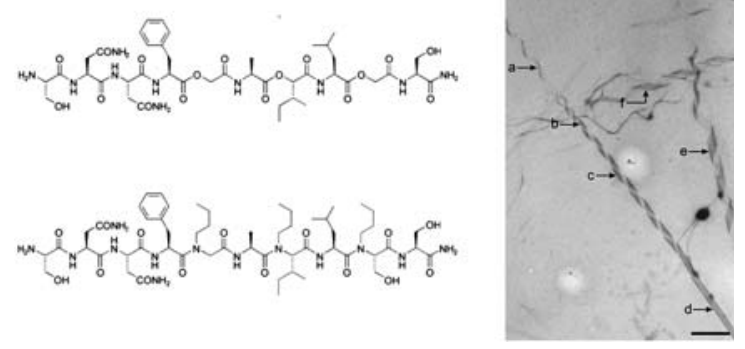

Fig. 13 The chemical structures of amylin derivatives. Both structures assembled into helical fibrils and nanotubes. (Scale bar: $2 \mu \mathrm{m}$ ) Reproduced with permission from ref. 109. 
growth of the belts. PVP adsorbs on the $\{111\}$ facets of the gold seeds, and the subsequent growth of the seeds on $\{110\}$ facets in the absence of PVP results in the formation of triangular plates through van der Waals forces. The triangular plates then recrystallize to form the nanobelts, which have the same thickness and angle end structure.

Nanowires self-assembled from molybdenum sulfur iodine were experimentally characterized by electron microscopy and computer-simulated to fully understand the structure and the forces acting on that structure. ${ }^{114}$ The electron microscopy images showed derivations from the previously predicted bundle structures, so the researchers proposed a new structure. The electronic properties of the wire was determined by density functional theory (DFT), which presented weak bonding between neigboring strands. This weak bonding, attributed to van der Waals forces, proved that the wires indeed assembled into the newly proposed structure. It is suggested that the interwire interaction is stabilized by Mo $d$-S $p$ hybridization and minimization of van der Waals forces.

\section{Conclusion}

Among the various materials in nanoscale, 1-D nanostructures such as nanofibers, nanowires and nanotubes have attracted tremendous attention. Nearly all materials, organic, inorganic or hybrid, have been used in the development of 1-D nanostructures. The dependence of inorganic nanostructures on ionic or metallic bonds to hold their structure together has enabled researchers to use various methods to synthesize uniform inorganic nanostructures. When it comes to organic nanostructures, the acting forces become weak forces, such as hydrogen bonding, van der Waals, and $\pi-\pi$ stacking; these forces inhibit the use of vapor deposition-like techniques as they do not yield homogenous structures. Although there are some studies involving organic nanostructures where vapor deposition or some solidphase reactions are used, techniques developed for inorganic structures are usually not applicable to organic ones. Selfassembly remains to be the leading mechanism for the design of 1-D organic nanostructures. In order to realize the enormous potential range of nanostructure applications, new nanofabrication capabilities, new methods for functionalization of molecules and more efficient bottom-up methods must be developed.

\section{Acknowledgements}

This work is supported in part by the Marie Curie IRG grant 231019 and TÜBITAK grant 109T603.

\section{References}

1 U. Feldkamp and C. M. Niemeyer, Angew. Chem., Int. Ed., 2006, 45, 1856-1876.

2 K. Rajagopal and J. P. Schneider, Curr. Opin. Struct. Biol., 2004, 14, 480-486.

3 S. Toksöz and M. O. Guler, Nano Today, 2009, 4, 458-469.

4 J. J. Hwang, S. N. Iyer, L.-S. Li, R. Claussen, D. A. Harrington and S. I. Stupp, Proc. Natl. Acad. Sci. U. S. A., 2002, 99, 9662-9667.

5 G. A. Silva, C. Czeisler, K. L. Niece, E. Beniash, D. A. Harrington, J. A. Kessler and S. I. Stupp, Science, 2004, 303, 1352-1355.

6 M. Metzke, N. O'Connor, S. Maiti and Z. Guan, Angew. Chem., Int. Ed., 2005, 44, 6529-6533.
7 K. Y. Lee, E. Alsberg, S. Hsiong, W. Comisar, J. Linderman, R. Ziff and D. Mooney, Nano Lett., 2004, 4, 1501-1506.

8 Y. Jin, N. Friedman, M. Sheves, T. He and D. Cahen, Proc. Natl. Acad. Sci. U. S. A., 2006, 103, 8601-8606.

9 S. T. Nguyen, D. L. Gin, J. T. Hupp and X. Zhang, Proc. Natl. Acad. Sci. U. S. A., 2001, 98, 11849-11850.

10 T. Scheibel, R. Parthasarathy, G. Sawicki, X.-M. Lin, H. Jaeger and S. L. Lindquist, Proc. Natl. Acad. Sci. U. S. A., 2003, 100, 45274532.

11 A. R. Hirst, B. Escuder, J. F. Miravet and D. K. Smith, Angew. Chem., Int. Ed., 2008, 47, 8002-8018.

12 S. V. N. T. Kuchibhatla, A. S. Karakoti, D. Bera and S. Seal, Prog. Mater. Sci., 2007, 52, 699-913.

13 J. Hu, T. W. Odom and C. M. Lieber, Acc. Chem. Res., 1999, 32, 435-445.

14 Y. Xia, P. Yang, Y. Sun, Y. Wu, B. Mayers, B. Gates, Y. Yin, F. Kim and H. Yan, Adv. Mater., 2003, 15, 353-389.

15 O. C. Rodriguez, A. W. Schaefer, C. A. Mandato, P. Forscher, W. M. Bement and C. M. Waterman-Storer, Nat. Cell Biol., 2003, 5, 599-610.

16 N. Kol, L. Adler-Abramovich, D. Barlam, R. Z. Shneck, E. Gazit and I. Rousso, Nano Lett., 2005, 5, 1343-1346.

17 J. W. Steed, Supramolecular chemistry, Wiley, Chichester, 2000.

18 M. Demir and M. H. B. Stowell, Nanotechnology, 2002, 13, 541.

19 Z. Li, S.-W. Chung, J.-M. Nam, D. S. Ginger and C. A. Mirkin, Angew. Chem., 2003, 115, 2408-2411.

20 M. Knez, A. M. Bittner, F. Boes, C. Wege, H. Jeske, E. Mai and K. Kern, Nano Lett., 2003, 3, 1079-1082.

21 C. Mao, D. J. Solis, B. D. Reiss, S. T. Kottmann, R. Y. Sweeney, A. Hayhurst, G. Georgiou, B. Iverson and A. M. Belcher, Science, 2004, 303, 213-217.

22 K. T. Nam, D.-W. Kim, P. J. Yoo, C.-Y. Chiang, N. Meethong, P. T. Hammond, Y.-M. Chiang and A. M. Belcher, Science, 2006, 312, 885-888.

23 R. H. Baughman, A. A. Zakhidov and W. A. de Heer, Science, 2002, 297, 787-792.

24 D. Tasis, N. Tagmatarchis, V. Georgakilas and M. Prato, Chem.Eur. J., 2003, 9, 4000-4008.

25 A. Hirsch, Angew. Chem., Int. Ed., 2002, 41, 1853-1859.

26 D. Tasis, N. Tagmatarchis, A. Bianco and M. Prato, Chem. Rev., 2006, 106, 1105-1136.

27 C. Thomsen and H. Kataura, New J. Phys., 2003, 5, DOI: 10.1088/ 1367-2630/5/1/E04.

28 J. M. Lehn, Supramolecular Chemistry, Wiley-VCH, 1995, ISBN 978-3527293117.

29 J. D. Hartgerink, E. R. Zubarev and S. I. Stupp, Curr. Opin. Solid State Mater. Sci., 2001, 5, 355-361.

30 C. F. J. Faul and M. Antonietti, Adv. Mater., 2003, 15, 673-683.

$31 \mathrm{M}$. Baars and E. Meijer, Host-Guest Chemistry of Dendritic Molecules, Springer Berlin/Heidelberg, 2000, 131-182.

32 H. Yokoi, T. Kinoshita and S. Zhang, Proc. Natl. Acad. Sci. U. S. A., 2005, 102, 8414-8419.

33 T. C. Holmes, S. de Lacalle, X. Su, G. Liu, A. Rich and S. Zhang, Proc. Natl. Acad. Sci. U. S. A., 2000, 97, 6728-6733.

34 F. Gelain, D. Bottai, A. Vescovi and S. Zhang, PLoS One, 2006, 1, el19.

35 A. L. Sieminski, C. E. Semino, H. Gong and R. D. Kamm, J. Biomed. Mater. Res., Part A, 2008, 87a, 494-504.

36 J. D. Hartgerink, E. Beniash and S. I. Stupp, Science, 2001, 294, 1684-1688.

37 J. C. Stendahl, M. S. Rao, M. O. Guler and S. I. Stupp, Adv. Funct. Mater., 2006, 16, 499-508.

38 K. L. Niece, J. D. Hartgerink, J. J. J. M. Donners and S. I. Stupp, J. Am. Chem. Soc., 2003, 125, 7146-7147.

39 K. Rajangam, H. A. Behanna, M. J. Hui, X. Han, J. F. Hulvat, J. W. Lomasney and S. I. Stupp, Nano Lett., 2006, 6, 2086-2090.

40 M. O. Guler, L. Hsu, S. Soukasene, D. A. Harrington, J. F. Hulvat and S. I. Stupp, Biomacromolecules, 2006, 7, 1855-1863.

41 R. M. Capito, H. S. Azevedo, Y. S. Velichko, A. Mata and S. I. Stupp, Science, 2008, 319, 1812-1816.

42 Y. Zimenkov, S. N. Dublin, R. Ni, R. S. Tu, V. Breedveld, R. P. Apkarian and V. P. Conticello, J. Am. Chem. Soc., 2006, 128, 6770-6771.

43 P. B. Harbury, P. S. Kim and T. Alber, Nature, 1994, 371, 80-83.

44 Z. Wang, C. J. Medforth and J. A. Shelnutt, J. Am. Chem. Soc., 2004, 126, 15954-15955. 
45 I. McKeogh, J. P. Hill, E. S. Collins, T. McCabe, A. K. Powell and W. Schmitt, New J. Chem., 2007, 31, 1882-1886.

46 N. Judas and B. Kaitner, Acta Crystallogr., Sect. E: Struct. Rep. Online, 2006, 62, m163-m165.

47 C.-S. Liu, L.-M. Zhou, L.-Q. Guo, S.-T. Ma and S.-M. Fang, Acta Crystallogr., Sect. C: Cryst. Struct. Commun., 2008, 64, m394-m397.

48 S. N. Collins, J. A. Krause, M. Regis, P. J. Ball and W. B. Connick, Acta Crystallogr., Sect. C: Cryst. Struct. Commun., 2007, 63, m528$\mathrm{m} 530$.

49 S. Burazerovic, J. Gradinaru, J. Pierron and Thomas R. Ward, Angew. Chem., Int. Ed., 2007, 46, 5510-5514.

50 B.-H. Ye, M.-L. Tong and X.-M. Chen, Coord. Chem. Rev., 2005, 249, 545-565.

51 A. Petitjean, L. A. Cuccia, M. Schmutz and J.-M. Lehn, J. Org. Chem., 2008, 73, 2481-2495.

52 S. N. Dublin and V. P. Conticello, J. Am. Chem. Soc., 2008, 130, 4951.

53 J. Dong, J. E. Shokes, R. A. Scott and D. G. Lynn, J. Am. Chem. Soc., 2006, 128, 3540-3542.

54 H. Dong, S. E. Paramonov and J. D. Hartgerink, J. Am. Chem. Soc., 2008, 130, 13691-13695.

55 L.-Y. Kong, X.-H. Lu, Y.-Q. Huang, H. Kawaguchi, Q. Chu, H.-F. Zhu and W.-Y. Sun, J. Solid State Chem., 2007, 180, 331-338.

56 E. D. Sone, E. R. Zubarev and S. I. Stupp, Angew. Chem., Int. Ed., 2002, 41, 1705-1709.

57 E. D. Sone, E. R. Zubarev and S. I. Stupp, Small, 2005, 1, 694-697.

58 H. Yan, S. H. Park, G. Finkelstein, J. H. Reif and T. H. LaBean, Science, 2003, 301, 1882-1884.

59 E. Braun, Y. Eichen, U. Sivan and G. Ben-Yoseph, Nature, 1998, 391, 775-778.

60 H. Fenniri, P. Mathivanan, K. Vidale, D. Sherman, K. Hallenga, K. Wood and J. Stowell, J. Am. Chem. Soc., 2001, 123, 3854-3855.

61 M. M. Conn and J. Rebek, Chem. Rev., 1997, 97, 1647-1668.

62 S. Scanlon and A. Aggeli, Nano Today, 2008, 3, 22-30.

63 J. D. Hartgerink, J. R. Granja, R. A. Milligan and M. R. Ghadiri, J. Am. Chem. Soc., 1996, 118, 43-50.

64 T. D. Clark, L. K. Buehler and M. R. Ghadiri, J. Am. Chem. Soc., 1998, 120, 651-656.

65 Y. S. Velichko, S. I. Stupp and M. O. de la Cruz, J. Phys. Chem. B, 2008, 112, 2326-2334.

66 S. E. Paramonov, H.-W. Jun and J. D. Hartgerink, J. Am. Chem. Soc., 2006, 128, 7291-7298.

67 M. O. Guler, J. K. Pokorski, D. H. Appella and S. I. Stupp, Bioconjugate Chem., 2005, 16, 501-503.

68 M. Reches and E. Gazit, Science, 2003, 300, 625-627.

69 O. Carny, D. E. Shalev and E. Gazit, Nano Lett., 2006, 6, 1594-1597.

70 B. H. Hong, S. C. Bae, C.-W. Lee, S. Jeong and K. S. Kim, Science, 2001, 294, 348-351.

71 B. H. Hong, J. Y. Lee, C.-W. Lee, J. C. Kim, S. C. Bae and K. S. Kim, J. Am. Chem. Soc., 2001, 123, 10748-10749.

72 T. Emrick and J. M. J. Fréchet, Curr. Opin. Colloid Interface Sci., 1999, 4, 15-23.

73 V. Percec, A. E. Dulcey, V. S. K. Balagurusamy, Y. Miura, J. Smidrkal, M. Peterca, S. Nummelin, U. Edlund, S. D. Hudson, P. A. Heiney, H. Duan, S. N. Magonov and S. A. Vinogradov, Nature, 2004, 430, 764-768.

74 E. R. Zubarev, M. U. Pralle, E. D. Sone and S. I. Stupp, J. Am. Chem. Soc., 2001, 123, 4105-4106.

75 B. W. Messmore, J. F. Hulvat, E. D. Sone and S. I. Stupp, J. Am. Chem. Soc., 2004, 126, 14452-14458.

76 E. R. Zubarev, M. U. Pralle, E. D. Sone and S. I. Stupp, Adv. Mater., 2002, 14, 198-203.

77 H. Frusawa, A. Fukagawa, Y. Ikeda, J. Araki, K. Ito, G. John and T. Shimizu, Angew. Chem., Int. Ed., 2003, 42, 72-74.

78 T. Shimizu, J. Polym. Sci., Part A: Polym. Chem., 2006, 44, 51375152.

79 M. A. Balbo Block, C. Kaiser, A. Khan and S. Hecht, "Discrete Organic Nanotubes Based on a Combination of Covalent and NonCovalent Approaches", 2005, Springer Berlin/Heidelberg, pp. 89-150.
80 N. Kameta, M. Masuda, H. Minamikawa, Y. Mishima, I. Yamashita and T. Shimizu, Chem. Mater., 2007, 19, 3553-3560.

81 J. Schnadt, E. Rauls, W. Xu, R. T. Vang, J. Knudsen, E. Laegsgaard, Z. Li, B. Hammer and F. Besenbacher, Phys. Rev. Lett., 2008, 100, 046103-046104.

82 S. Grimme, Angew. Chem., Int. Ed., 2008, 47, 3430-3434.

83 J. S. Moore, Acc. Chem. Res., 1997, 30, 402-413.

84 S. Höger, J. Polym. Sci., Part A: Polym. Chem., 1999, 37, 2685-2698. 85 D. Pasini and M. Ricci, Curr. Org. Synth., 2007, 4, 59-80.

86 D. Zhao and J. S. Moore, Chem. Commun., 2003, 807-818.

87 B.-B. Ni, Q. Yan, Y. Ma and D. Zhao, Coord. Chem. Rev., 2010, 254, 954-971.

88 L. Zang, Y. Che and J. S. Moore, Acc. Chem. Res., 2008, 41, 15961608.

89 K. Balakrishnan, A. Datar, W. Zhang, X. Yang, T. Naddo, J. Huang, J. Zuo, M. Yen, J. S. Moore and L. Zang, J. Am. Chem. Soc., 2006, 128, 6576-6577.

90 B. Gong, A. Sanford and J. Ferguson, "Enforced Folding of Unnatural Oligomers: Creating Hollow Helices with Nanosized Pores", Springer Berlin/Heidelberg, 2007, pp. 1-29.

91 A. J. Helsel, A. L. Brown, K. Yamato, W. Feng, L. Yuan, A. J. Clements, S. V. Harding, G. Szabo, Z. Shao and B. Gong, J. Am. Chem. Soc., 2008, 130, 15784-15785.

92 H. Engelkamp, S. Middelbeek and R. J. M. Nolte, Science, 1999, 284, 785-788.

93 M. D. Curtis, J. Cao and J. W. Kampf, J. Am. Chem. Soc., 2004, 126, $4318-4328$

94 J. Cornil, D. Beljonne, J.-P. Calbert and J.-L. Brédas, Adv. Mater., 2001, 13, 1053-1067.

95 A. L. Briseno, S. C. B. Mannsfeld, S. A. Jenekhe, Z. Bao and Y. Xia, Mater. Today, 2008, 11, 38-47.

96 F. Fages, J. A. Wytko and J. Weiss, C.R. Chim., 2008, 11, 1241-1253.

97 A. P. H. J. Schenning and E. W. Meijer, Chem. Commun., 2005, $3245-3258$.

98 S. Xiao, J. Tang, T. Beetz, X. Guo, N. Tremblay, T. Siegrist, Y. Zhu, M. Steigerwald and C. Nuckolls, J. Am. Chem. Soc., 2006, 128, 10700-10701.

99 J. P. Hill, W. Jin, A. Kosaka, T. Fukushima, H. Ichihara, T. Shimomura, K. Ito, T. Hashizume, N. Ishii and T. Aida, Science, 2004, 304, 1481-1483.

100 M. L. Bushey, T.-Q. Nguyen and C. Nuckolls, J. Am. Chem. Soc., 2003, 125, 8264-8269.

101 M. N. Rodnikova, J. Mol. Liq., 2007, 136, 211-213.

102 J. D. Hartgerink, E. Beniash and S. I. Stupp, Proc. Natl. Acad. Sci. U. S. A., 2002, 99, 5133-5138.

103 H. Xu, J. Wang, S. Han, J. Wang, D. Yu, H. Zhang, D. Xia, X. Zhao, T. A. Waigh and J. R. Lu, Langmuir, 2009, 25, 4115-4123.

104 S. Cavalli and A. Kros, Adv. Mater., 2008, 20, 627-631.

105 J. T. Meijer, M. Roeters, V. Viola, D. W. P. M. Löwik, G. Vriend and J. C. M. van Hest, Langmuir, 2007, 23, 2058-2063.

106 E. Kokkoli, A. Mardilovich, A. Wedekind, E. L. Rexeisen, A. Garg and J. A. Craig, Soft Matter, 2006, 2, 1015-1024.

107 H. Cui, M. J. Webber and S. I. Stupp, Peptide Science, 2010, 94, 118.

108 Y.-Y. Won, H. T. Davis and F. S. Bates, Science, 1999, 283, 960-963.

109 R. C. Elgersma, T. Meijneke, G. Posthuma, D. T. S. Rijkers and R. M. J. Liskamp, Chem.-Eur. J., 2006, 12, 3714-3725.

110 M. E. Cates, Macromolecules, 1987, 20, 2289-2296.

111 J. W. M. Hoppener, B. Ahren and C. J. M. Lips, N. Engl. J. Med., 2000, 343, 411-419.

112 P. Westermark, U. Engström, K. H. Johnson, G. T. Westermark and C. Betsholtz, Proc. Natl. Acad. Sci. U. S. A., 1990, 87, 5036-5040.

113 J. Zhang, H. Liu, Z. Wang and N. Ming, Appl. Phys. Lett., 2007, 91, 133112-133113.

114 V. Nicolosi, P. D. Nellist, S. Sanvito, E. C. Cosgriff, S. Krishnamurthy, W. J. Blau, M. L. H. Green, D. Vengust, D. Dvorsek, D. Mihailovic, G. Compagnini, J. Sloan, V. Stolojan, J. D. Carey, S. J. Pennycook and J. N. Coleman, Adv. Mater., 2007, 19, 543-547. 